\title{
EFEITO DA DENSIDADE DE POPULAÇÃO SOBRE OS TEORES DE CARBOIDRATOS SOLÚVEIS E ÁCIDO ASCÓRBICO DE REPOLHO (Brassica oleracea var. capitata)*
}

\author{
Luiz Eduardo Gutierrez ** \\ KEIGO MINAMI *** \\ MASSAR KATAYAMA **** \\ ILENE R. DA SILVA***** \\ WILSON P. CÉSAR JR.**
}

\section{RESUMO}

Amostras de repolho (Brassica oleracea var. capitata) de densidade de 20.833, 25.641, 37.037, 55.555 e 111.111 plantas/ha foram analisadas quanto aos teores de ácido ascórbico e carboidratos solúveis. Não foram observadas diferenças significativas entre estes teores nas densidades de população utilizadas. O teor médio de ácido ascórbico foi $25,8 \mathrm{mg} / 100 \mathrm{~g}$ peso fresco. Os principais constituintes da fração carboidratos solúveis foram sacarose, glucose e frutose, perfazendo acima de $80 \%$ do total. Os teores médios de! carboidratos solúveis, expressos em $\mathrm{g} / 100 \mathrm{~g}$ de peso fresco foram os seguintes carboidratos solúveis totais $(4,60)$, sacarose $(0,45)$, glucose $(1,94)$ e frutose $(1,83)$.

\section{INTRODUÇÃO}

Segundo dados citados por FRANCO (1960) e CRAWFORD (1966) pode-se verificar que as hortaliças apresentam para a alimentação, a função principal de fornecer vitaminas e sais minerais, pois os teores de proteínas, carboidratos e lipídeos são considerados muito baixos em relação a outros alimentos. Este fato possivelmente justificaria o número relativamentè pequeno de referências sobre os teores de carboidratos em hortaliças.

\footnotetext{
* Entregue para publicação em: 24/9/1976

* Departamento de Química, E.S.A. "Luiz de Queiroz"

** Departamento de Agricultura e Horticultura da ESALQ

*** Estagiário junto ao Depto. de Agricultura e Horticultura

**** Estagiários junto ao Departamento de Química.
} 
No Estado de São Paulo, a região que mais produz repolho é Ibiúna e segundo o Instituto de Economia Agrícola, em 1974, São Paulo colheu 109.050 ton em uma área de 3691 ha, sendo uma das hortaliças mais negociadas na Companhia de Entrepostos e Armazens Gerais do Estado de São Paulo (ANÔNIMO, 1976).

HOWARD et alii (citado por MORTENSEN \& BULLARD, 1971) verificaram para repolho cultivado na Califórnia, diferenças nos teores de vitamina $\mathrm{C}$ entre as variedades Branco, Vermelho e Savoy. Os autores não detectaram diferenças nos teores de açúcar total entre repolho Branco e Vermelho.

O tempo decorrido entre a colheita e a análise é importante para o teor de ácido ascórbico de repolho, McMILLAN \& TODHUNTER (1946) verificaram uma perda de 5,8\% neste teor depois de 120 minutos de colheita.

RAM et alii (1973) verificaram que a pulverização de repolho com ácido naftaleno acético em doses de 0 a $100 \mathrm{ppm}$ provocaram aumento no teor de ácido ascórbico em todos os tratamentos. A fertilização nitrogenada também pode afetar o conteúdo em ácido ascórbico de repolho como observado por SRIVASTAVA et alii (1970) em que teores. elevados foram obtidos com doses de $300 \mathrm{~kg}$ de $\mathrm{N}$, sendo o mesmo fato relatado por RAM e SHARMA (1969).

SHALLENBERGER (1970) verificou que em repolho o teor de glucose foi duas vezes maior do que frutose. WALI \& HASSAN (1965) verificaram qualitativamente a presença de glucose, frutose, sacarose e arabinose em amostras de repolho sendo que glucose foi detectada em teor maior.

O nível de fertilizantes não afetou significativamente os teores de açúcares totais em repolho porém o teor de ácido ascórbico foi significativamente maior com doses de NPK (JANKOVSK.JA, 1967).

No presente trabalho foram estudados os efeitos do espaçamento sobre os teores de carboidratos solúveis e ácido ascórbico. O conhecimento da composição em açúcares é importante para nutrição, pois BROOK \& NOEL (1969) mostraram que a ingestão de frutose pode levar a aumento de deposição de gordura corporal. Os teores de colesterol podem ser aumentados quando o carboiarato da dieta é sacarose ao invés de glicose ou amido (ANÔNIMO, 1969).

\section{MATERIAL E MÉTODOS}

Amostras de repolho (Brassica oleracea var. capitata) foram obtidas de um experimento com as seguintes densidades de plantas: 


Tratamento A -20.833 plantas/hectare
Tratamento $\mathrm{B}-25.641$
Tratamento $\mathrm{C}-37.037$
Tratamento $\mathrm{D}-55.555$
Tratamento $\mathrm{E}-111.111$

A cultivar usada foi Natsu-maki, híbrido de origem japonesa.

O plantio foi realizado em latossolo pertencente ao Departamento de Agricultura e Horticultura da E.S.A. "Luiz de Queiroz", tendo recebido $20 \mathrm{~g}$ por cova de adubo de fórmula 4-14-8 e $5 \mathrm{~g}$ por cova de $\mathrm{N}$ em cobertura aos 20, 40 e 60 dias após o transplante. Foram feitas ainda uma aplicação bórax em pulverização.

Imediatamente após o corte, as amostras foram picadas e separadas em três porções para as análises de matéria seca, carboidratos solúveis e ácido ascórbico.

A matéria seca foi obtida por secagem das amostras a $100-150^{\circ} \mathrm{C}$ em estufa até peso constante.

O teor de ácido ascórbico foi determinado utilizando-se o método de 2,6 dicloro fenol-indofenol descrito por JACOBS (1958).

Carboidratos solúveis foram extraídos com água fervente em banho-maria por 30 minutos após homogenização em Virtz por 3 minutos. Os teores foram determinados pelo método do fenol-sulfúrico descrito por DUBOIS et alii (1956).

Para a separação e identificação de açúcares foi adotada a técnica cromatográfica de ARZOLLA \& FONSECA (1965). E a quantificação foi realizada com o método descrito por DUBOIS et alii (1956).

Para análise estatística foi adotado o delineamento de blocos casualizados com 4 repetições (PIMENTEL GOMES, 1970) e adotado o nível de $5 \%$ de significância para comparação das médias nos teste $\mathrm{F}$ e Tukey.

\section{RESULTADOS E DISCUSSÃO}

No QUADRO 1 são apresentados os teores de matéria seca das amostras de repolho e observa-se que não foram detectadas diferenças significativas entre os tratamentos, embora a densidade de 37.037 plantas/ha tenha apresentado maior nível.

Inúmeros fatores podem afetar a composição de hortaliças, assim os teores de caroteno e carboidratos de cenoura foram afetados pelo 
cultivar, data de plantio, época de colheita e temperatura da estação (BRADLEY \& DYCK, 1968; CARLTON \& PETERSON, 1963).

No presente trabalho, o efeito do espaçamento não provocou alterações significativas nos teores de ácido ascórbico e carboidratos solúveis como pode ser observado nos QUADROS de números 2 a 6.

Os teores de carboidratos solúveis totais apresentados no QUADRO 3 foram superiores aos citados por HOWARD et alii para repolhos cultivados na Califórnia.

No QUADRO 7 observamos que a proporção de sacarose, glucose e frutose obedecem a uma proporção aproximadamente igual a 0,5:2:2. Estes dados não estão de acordo com SHALLEN BERGER (1970) que verificou que o teor de glucose foi duas vezes maior do que frutose e 20 vezes maior do que sacarose. Também WALI \& HASSAN (1965) verificaram qualitativamente em repolho, que o nível de glucose foi maior do que frutose, tendo detectado também arabinose.

Os dados de carboidratos solúveis totais apresentados por THOMPSON \& KELLY (1957) para repolho foram relativamente inferiores aos citados no QUADRO 3.

Os teores de ácido ascórbico do QUADRO 2 estão de acordo com os obtidos por HOWARD et alii para o cultivar Savoy e inferiores aos apresentados por MCMILLAN \& TODHUNTER (1946) e LAMPITT et alii (1950) para repolhos da Inglaterra e África do Sul. As diferenças encontradas entre os teores de ácido ascórbico do presente trabalho e da literatura poderiam ser explicadas pelo nível de adubação, pois SRIVASTAVA et alii (1970) verificou que o teor máximo de vitamina $\mathrm{C}$ foi obtido com doses de $300 \mathrm{~kg}$ de $\mathrm{N}$.

No QUADRO 7 observa-se que a percentagem de açúcares simples sobre o total aumentou com a densidade das plantas embora não fossem detectadas diferenças significativas. Este fato poderia indicar a formação de outros tipos de carboidratos como amido e que não foram analisados neste trabalho.

Em todos os tratamentos os principais constituintes da fração carboidratos solúveis foram: sacarose, glucose e frutose.

\section{CONCLUSÃO}

Os dados obtidos no presente trabalho demonstram que as diversas densidades de plantas utilizadas não apresentaram efeitos significativos sobre a matéria seca, e os teores de ácido ascórbico e carboidratos solúveis de repolho. 
QUADRO 1 - Matéria seca de amostras de repolho obtidas de diversas densidades de plantas.

\begin{tabular}{cccccr}
\hline \multirow{2}{*}{ Repetições } & \multicolumn{5}{c}{ Tratamentos $\left(^{*}\right)$} \\
\cline { 2 - 6 } & A & B & C & D & E \\
\hline \multirow{2}{*}{1} & 8,52 & 8,33 & 9,74 & 7,88 & 7,53 \\
2 & 8,28 & 9,56 & 8,73 & 8,45 & 10,84 \\
3 & 8,77 & 8,65 & 9,43 & 8,98 & 8,74 \\
4 & 8,96 & 8,99 & 9,12 & 9,17 & 6,85 \\
\hline Médias & 8,63 & 8,88 & 9,25 & 8,62 & 8,49 \\
\hline
\end{tabular}

(*) Consultar a secção Material e Métodos
C.V. $=10,48 \%$
F não significativo

QUADRO 2 - Teores de ácido ascórbico de amostras de repolho obtidas de diversas densidades de plantas (Expresso em $\mathrm{mg} / 100 \mathrm{~g}$ peso fresco).

\begin{tabular}{cccccc}
\hline \multirow{2}{*}{ Repetições } & \multicolumn{5}{c}{ Tratamentos } \\
\cline { 2 - 6 } & $\mathrm{A}$ & $\mathrm{B}$ & $\mathrm{C}$ & $\mathrm{D}$ & $\mathrm{E}$ \\
\hline \multirow{2}{*}{1} & 34,4 & 18,2 & 26,5 & 25,8 & 19,6 \\
2 & 15,0 & 22,3 & 19,8 & 22,7 & 31,8 \\
3 & 25,8 & 25,0 & 23,0 & 23,4 & 18,8 \\
4 & 31,5 & 35,1 & 36,9 & 36,0 & 24,3 \\
\hline Médias & 26,7 & 25,1 & 26,5 & 27,0 & 23,6 \\
\hline
\end{tabular}

$\mathrm{C} . \mathrm{V} .=22,96 \% \quad \mathrm{~F}$ não significativo

QUADRO 3 - Teores de carboidratos solúveis totais de amostras de repolho obtidas de diversas densidades de plantas (Expresso em $\mathrm{g} / 100 \mathrm{~g}$ peso fresco).

\begin{tabular}{cccccc}
\hline \multirow{2}{*}{ Repetições } & \multicolumn{5}{c}{ Tratamentos } \\
\cline { 2 - 6 } & $\mathrm{A}$ & $\mathrm{B}$ & $\mathrm{C}$ & $\mathrm{D}$ & $\mathrm{E}$ \\
\hline \hline 1 & 4,33 & 5,05 & 4,08 & 4,84 & 4,55 \\
2 & 5,09 & 4,75 & 5,02 & 4,24 & 4,22 \\
3 & 4,86 & 4,51 & 4,72 & 4,54 & 4,33 \\
4 & 5,34 & 5,04 & 4,56 & 3,59 & 4,41 \\
\hline Médias & 4,90 & 4,84 & 4,59 & 4,30 & 4,38 \\
\hline
\end{tabular}

C.V. $=9,11 \%$

F não significativo 
QUADRO 4 - Teores de sacarose de amostras de repolho obtidas de diversas densidades de plantas (Expresso em $\mathrm{mg} / 100 \mathrm{~g}$ peso fresco).

\begin{tabular}{cccccc}
\hline \multirow{2}{*}{ Repetições } & \multicolumn{5}{c}{ Tratamentos } \\
\cline { 2 - 6 } & $\mathrm{A}$ & $\mathrm{P}$ & $\mathrm{C}$ & $\mathrm{D}$ & $\mathrm{E}$ \\
\hline \hline 1 & 0,55 & 0,61 & 0,33 & 0,41 & 0,27 \\
2 & 0,43 & 0,38 & 0,64 & 0,65 & 0,65 \\
3 & 0,37 & 0,36 & 0,47 & 0,32 & 0,37 \\
+ & 0,46 & 0,47 & 0,47 & 0,30 & 0,48 \\
\hline Médias & 0,45 & 0,45 & 0,48 & 0,42 & 0,44 \\
\hline
\end{tabular}

C.V. $=27,43 \% \quad$ F não significativo

QUADRO 5 - Teores de glucose de amostras de repolho obtidas de diversas densidades de plantas (Expresso em $\mathrm{mg}^{\prime} / 100 \mathrm{~g}$ peso fresco).

\begin{tabular}{cccccc}
\hline & \multicolumn{5}{c}{ Tratamentos } \\
\cline { 2 - 6 } Repetições & $\mathrm{A}$ & $\mathrm{B}$ & $\mathrm{C}$ & $\mathrm{D}$ & $\mathrm{E}$ \\
\hline 1 & 1,67 & 2,33 & 1,97 & 2,11 & 2,09 \\
2 & 2,24 & 1,89 & 1,68 & 1,75 & 1,80 \\
3 & 1,92 & 1,82 & 1,76 & 1,61 & 1,90 \\
4 & & & & & \\
\hline Médias & 1,99 & 2,06 & 1,82 & 1,84 & 1,99 \\
\hline
\end{tabular}

C.V. $=10,49 \% \quad$ F não significativo

QUADRO 6 - Teores de frutose de amostras de repolho obtidas de diversas densidades de plantas (Expresso em $\mathrm{mg} / 100 \mathrm{~g}$ peso fresco).

\begin{tabular}{cccccc}
\hline \multirow{2}{*}{ Repetições } & \multicolumn{5}{c}{ Tratamentos } \\
\cline { 2 - 6 } & $\mathrm{A}$ & $\mathrm{B}$ & $\mathrm{C}$ & $\mathrm{D}$ & $\mathrm{E}$ \\
\hline \hline 1 & 2,03 & 1,49 & 1,39 & 1,81 & 2,09 \\
2 & 1,61 & 1,73 & 1,90 & 2,01 & 1,80 \\
3 & 1,69 & 1,86 & 1,93 & 1,72 & 2,18 \\
4 & 2,31 & 2,16 & 1,46 & 1,88 & 1,61 \\
\hline Médias & 1,91 & 1,81 & 1,67 & 1,85 & 1,92 \\
\hline
\end{tabular}

$\mathrm{C} \cdot \mathrm{V} .=15,72 \%$

F não significativo 
QUADRO 7 - Carboidratos solúveis de amostras de repolho obtidas de diversas densidades de plantas (Expresso em $\mathrm{mg} / 100 \mathrm{~g}$ peso fresco).

\begin{tabular}{lccccc}
\hline \multirow{2}{*}{ Carboidratos } & \multicolumn{5}{c}{ Tratamentos } \\
\cline { 2 - 6 } & $\mathrm{A}$ & $\mathrm{B}$ & $\mathrm{C}$ & $\mathrm{D}$ & $\mathrm{E}$ \\
\hline \hline Solúveis Totais & 4,90 & 4,84 & 4,59 & 4,30 & 4,38 \\
Sacarose & 0,45 & 0,45 & 0,48 & 0,42 & 0,44 \\
Glucose & 1,99 & 2,06 & 1,82 & 1,84 & 1,99 \\
Frutose & 1,91 & 1,81 & 1,67 & 1,85 & 1,92 \\
Açúc. livres & & & & & \\
\hline \multicolumn{1}{c}{ Totais } & 88,8 & 89,2 & 86,5 & & 95,3 \\
\hline
\end{tabular}

\section{SUMMARY}

TE EFFECT OF PLANT POPULATION DENSITY ON SOLUBLE CARBOHYDRATES AND ASCORBIC ACID CONTENTS OF CABBAGE (BRASSICA OLERACEA CV. CAPITATA).

Cabbage (Brassica olcracea CV. capitata) samples from 20.833, 25.641, 37.037, 55.555 and 111.111 plants/ha densities were analysed $\mathrm{cn}$ ascorbic acid and soluble carbohydrates contents. Statistically difierences were not observed between those levels and plant densities. The mean level ascorbic acid was $25.8 \mathrm{mg} / 100 \mathrm{~g}$ on fresh weight. The principal constituents of soluble carbohydrates fraction were sucrose, glucose and fructose. These sugars were represented by $80 \%$ of total soluble carbohydrates. The mean values of soluble carbohydrates on fresh weight basis, were total (4.60), sucrose $(0.45)$, glucose $(1.94)$ and fructose $(1.83)$.

\section{LITERATURA CITADA}

ANÔNIMO, 1969. Many Variants in body reactions to carbohydrates. Agricultural Research, 3-4.

ANÔNIMO, 1976. Repolho: várias regióes propícias ao seu cultivo. Dirigente Rural, $X V: 28-30$.

ARZOLLA, J.D.P. e H. FONSECA. 1965. Cromatografia de açúcares. Boletim Didático n. ${ }^{\circ}$ 7. E.S.A. "Luiz de Queiroz". 19 p.

BRADLEY, G.A. and R.L. DYCK. 1968. Carrot color and carotenoids as affected by variety and growing conditions. Proc. Amer. Soc. Hort. Sci., 93: 402-407.

BROOK, M. and P. NOEL. 1969. Influence of dietary liquid glucose, sucrose and fructose on body fat formation. Nature, 222: $562-563$. 
CARLTON, B.C. and C.E. PETERSON. 1963. Breeding cariots for sugar and dry matter content. Proc. Amer. Soc. Hort. Sci., 82: 332-340.

CRAWFORD, A.M.D. 1966. Alimentos, Seleção e Preparo. Distribuidora Record de Serviços de Imprensa. Rio de Janeiro., 387 p.

DUBOIS, M., K.A. GILlES, J.K. HAMILTON, P.A. REBERS and F. SMITH. 1956. Colorimetric methods for determination of sugars and related substances. Anal. Chem., 28: $350-356$

FRANCO, G. 1960. Tabela de Composição Química de Alimentos. 3. ${ }^{\mathrm{a}}$ ed. Serviço de Alimentação da Previdência Social (SAPS). - Rio de Janeiro. 194 p.

HOWARD, F., J.H. MACCILLIVRAY y M. YAMAGUCCHI. La Composicion en Nutrimientes de Hortalizas Cultivadas en California. Boletim n. ${ }^{\circ} 788$. Estación 1971. Horticulture Tropical y Subtrópical. 2. ${ }^{\mathrm{a}}$ ed. Ed. Galve. México. $182 \mathrm{p}$.

Agrícola Experimental de California. In: MORTENSEN, E., and E. BULLARD.

JACOBS, M.B. 1058. The Chemical Analysis of Foods and Foods Products. Van Nostrand. New York. $071 \mathrm{p}$.

JANKOVSKAJA, N.M. 1967. The effect of fertilizers on the chemical composition cabbages and cariots. Himija sel. Hoz., 5: 11-13. In Horticultural Abstracts, 38: 706.

LAMPITT, L.M., L. GINSBURG and L.C. BAKER, 1950. The vitamin C content of english and south african cabbages. J. Sci. Food Agric., 1: 12-14.

McMILLAN, J. and E.N. TODHUNTER. 1946. Dehydroascorbic acid in cabbage. Science, 103 : 196-197.

MORTENSEN, E. e E. BULLARD. 1971. Horticultura Tropical y Subtropical. 2.a ed. Editora Galve. México. 182 p.

PIMENTEL GOMES, F. 1970. Curso de Estatística Experimental. 4. ${ }^{a}$ ed. Livraria Nobel. São Paulo. 430 p. .

RAM K. and R.K. SHARMA. 1969. Effect of nitrogen supply on growth, yield and ascorbic acid content of cabbage (Brassica oleracea var. capitata Linn). Poona agric. Coll. Mag. 59: 25-29. In: Horticultural Abstracts, 40: 741.

RAM, K., A.N. VERMA and R.K. SHARMA. 1973. Effect of naphthalene acetic acid on growth, yield, protein and ascorbic acid content of cabbage (Brassica oleracea var. capitata Linn.). Plant Science, 5: 150-152. In: Horticultural Abstracts, 46: 294.

SHALLENBERGER, R.S. 1970. Nutritional quality in fruits and vegetables. Hort Science, 5 : 100-101.

SRIVASTAVA, D.C., A.N. VERMA, H.R. MISHRA and R.K. SHARMA. 1970. Growth, yield, protein and ascorbic acid contents of cabbage (Brassica oleracea var. capitata) as affected by different levels of nitrogen. Plant Science, 2: 132-134. In: Horticultural Abstracts, 43 : 30.

WALI, Y.A. and Y.M. HASSAN. 1965. Qualitative chromatographic survey of the sugars prevailing in rosse horticultural crops. Proc. Amer. Soc. Hort. Sci., 87: 264-269. 